\title{
EVALUATING THE COMPRESSIVE STRENGTH OF CONCRETE CONTAINING RECYCLED AGGREGATE IN DIFFERENT CURING CONDITIONS
}

\author{
Sadaf NOSHIN ${ }^{\text {a,*, }}$, M. Adil KHAN ${ }^{\text {a }}$, M. SALMAN ${ }^{\text {a }}$, M. SHAHZAD ASLAM ${ }^{\text {a }}$, Haseeb \\ AHMAD $^{\text {a }}$, Atteq Ur REHMAN ${ }^{\text {a }}$, Humaira KANWAL ${ }^{\text {a }}$, Abrar AHMAD ${ }^{b}$ \\ ${ }^{a}$ Department of Technology The University of Lahore, ${ }^{b}$ Deputy Director in NTDC Department, Pakistan, E-mails: \\ *sadaf.noshin@tech.uol.edu.pk, adee.uol@gmail.com, muhammad.salman@tech.uol.edu.pk, \\ muhammad.aslam5@tech.uol.edu.pk,hmughal84@gmail.com, haseeb.ahmad1@tech.uol.edu.pk, \\ atteq.urehman@tech.uol.edu.pk, abrar.engr@gmail.com
}

Received: 23.08.2021 / Accepted: 21.09.2021 / Revised: 25.09.2021 / Available online: 15.12.2021

DOI: 10.2478/jaes-2021-0017

Key Words: Recycled aggregate concrete, Rice husk ash, Workability test, Rapid curing, Acid curing, Compressive strength.

\begin{abstract}
In construction industry, demolished construction waste is recently used as reprocessed aggregate to produce environmentally friendly concrete which is a good substitute to normal crush due to increased demand of ecological growth and conservation benefits. Though, the properties of recycled aggregate concrete are smallest as compared to concrete produced from natural aggregate and these properties can be enhanced by adding some materials having cementitious properties. Rice husk ash (RHA) is used as partial replacement of cement in recycled aggregate concrete to improve the properties as well as to conserve the natural resources. The elementary purpose of this investigation is to determine the compressive strength of concrete by the replacement of cement with different percentages of rice husk ash such as $0 \%, 7.5 \%, 10 \%, 12.5 \%, 15 \%$, and $17.5 \%$ respectively with different curing conditions. For the experimental program approximate 198 cylinders ( 18 for rapid curing, 90 for normal water curing and 90 for acid curing) are casted with the mix proportion of 1:2:4 and water to cement ratio of 0.50 whereas curing is done at the ages of 3,7,14,21 and 28 days. Various experiments are performed on fresh and hardened concrete to determine the effects of rice husk ash on recycled aggregate concrete with different curing conditions. Linear regression analysis is carried out to determine the compressive strength of concrete. It is pragmatic from the slump test results that the workability of recycled aggregate concrete is decreased by increasing the quantity of rice husk ash. This reduction in slump is due to high water absorption of recycled aggregates and rice husk ash. Further, the compressive strength of recycled aggregate concrete with normal and acid curing is decreased by increasing the percentages of rice husk ash. It is also observed that at 28- days of normal water curing for mix M1,M2,M3,M4,M5 and M6 the compressive strength is increased by $0.96 \%, 2.74 \% 1.45 \%, 4.50 \%, 4.23 \%$ and $4.22 \%$ respectively as compared to the compressive strength values at 28 days of acid water curing. Therefore, it is concluded that recycled aggregate concrete with 10 to $12 \%$ of rice husk ash is suitable for properties of concrete. The acid water curing has negative impacts on hardened properties of concrete as it reduced the compressive strength of concrete as compared to normal water curing.
\end{abstract}

\section{INTRODUCTION}

At present, it is very important to provide global awareness about the building materials that consume more energy and has a damaging effect on environmental sustainability. There is a lot of detailed information available in published form which is helpful to observe climatic condition variation, rise in $\mathrm{CO} 2$ production and damaging impact on ecosystem. To maintain the environmental sustainability, it is very important to utilize the waste materials including agricultural, construction and industrial waste which possess less damaging effects on environment. (Akinyemi, B. 2020)
It is a great responsibility of Building trade and other communities to maintain the environmental sustainability for the human health and safety (Terela, E, et al 2020) Construction and demolition waste is easily available waste throughout the world. The disposal of such waste not only affects the environment as well as its disposal increases the use of natural resources. The easiest method which is adopted throughout the world for its disposal is the landfilling, nevertheless it raises the load on heaping and landfilling progression because of its massive volume.

* Corresponding Author: Sadaf Noshin, E-mail: sadaf.noshin@tech.uol.edu.pk 
As the time passes, the hazardous material present in construction and demolition waste is caused severe ecological issues. As an alternative, recycling or reusing is the best solution to reuse such waste and reduces the burden on land as well as secure our environmental sustainability (García-González, J, et al.2014, Ben N,et al.2019 , Jayakody, S , et al.2018 , Hadavand, B et al.2019)

Using aggregates repossessed from structure and destruction surplus in construction may solve numerous issues linked to the construction manufacturing, for example lack of normal aggregates and shortage of land for dumping of construction waste (Abdel-Hay et al 2017, Padhi, R et al.2017).

Recycled aggregate concrete is made by crushing concrete from demolition waste to obtain recycled aggregates; however, due to the presence of plaster, its properties are inferior to the natural aggregate concrete. In recycled aggregate concrete, recycled aggregates are used to partially or fully replace coarse and fine aggregates. Though it is mainly used in low-rise construction, nevertheless it is cost effective, ecologically responsive, and drops landfill managing difficulties. (Khaoula, N.et al 2018, Ramadan Saleh Lamein, F. et al 2015. Adnan, Suraya .H et al.2007, Padhi, R et al.2018)

The effects of workability and strength of recycled aggregate concrete were studied by a number of researchers. Due to the high water absorbing potential of recycled aggregates, the workability of concrete containing recycled coarse aggregate was lower than that of natural aggregate concrete. This problem can be solved by adding admixtures or increasing the water cement ratio, which is related to aggregate absorption and presoaking. The slump loss should be controlled by presoaking the recycled coarse aggregates for approximate 20 minutes in some quantity of water which is estimated before for mixing of concrete. It helps to reduce the water absorption requirement of recycled coarse aggregates. (Padhi, R et al.2017, Padhi, R et al.2018, Fawzy, Yasser .A 2018)

In the past, the ordinary Portland cement was considered as an essential and distinctive ingredient of concrete and still it is an important part of concrete and mortar. It has been discovered that the processing of Portland cement releases carbon dioxide into the atmosphere, accounting for around 7 to $8 \%$ of all carbon dioxide emitted globally. The binding material that is commonly used in construction is the cinder cement, and its continuous demand increases the production and consumption rate and its annual output is estimated as above 4.1 billion tons in 2018. Because of the calcination and burring process of the raw materials, it is generally assumed that each tons of clinker cement manufactured has a carbon footprint of nearly $950 \mathrm{~kg}$ to 1.02 tonnes of $\mathrm{CO} 2$. The cement manufacturing industry produces approximately 4 billion tons of $\mathrm{CO} 2$ annually in the atmosphere. Currently, a variety of additional cementing and mineral admixtures such as bagasse ash (BA), fly ash (FA), rice husk ash (RHA), volcanic ash (VA), ground granulated blast slag (GGBS), glass powder (GP), natural pozzolana (NP), silica fume (SF), and Metakaolin (MK) are routinely integrated in mortar as a partial replacement for
PC to improve mechanical and durability performances, and minimize the cost of manufacturing industry in terms of environmental charges. Because of the various durability benefits and environmental legislation provided by mixed types of cement, they have become a popular alternative to plain cement. This reduces the loss of biodiversity. (Meddah, M. S., et al.2020, Koushkbaghi, Mahdi, et al 2019, Praveenkumar, T. R et al, 2019)

Rice husk is a cultivated waste product which is about 20 percent of the total production of rice annually throughout the world. Rice husk may be burned to create ash which meets the physical and chemical properties of inorganic admixtures. (Kulkarni, Makarand S, et al 2014 Habeeb, G. A. 2010). Due to the availability of different categories of paddy, harvest season, climatic and topographical condition, its chemical composition fluctuates from sample to sample (Praveenkumar, T. R et al, 2019, Habeeb, G. A. 2010). The discharge of CO2 is reduced by decreasing the production rate of cement and maintains the environmental sustainability by using the rice husk ash as partial replacement of cement. It has been discovered by various investigators that the slump value is maintained by increasing the water quantity and the addition of plasticizers by increasing the rice husk ash percentages. Concrete containing 10\% RHA had a lower compressive strength for up to 28 days, during which it had the same or higher strength than the control mix. At the early ages of curing, the compressive strength of concrete is reduced as the percentage of rice hush ash is increased such as related to ordinary concrete. It is observed that the strength of concrete is increased by the use of rice husk ash after the curing days increased owing to the incidence of great silica material. The silica in RHA reacted with $\mathrm{Ca}$ ions and $\mathrm{OH}$ ions to create $\mathrm{C}-\mathrm{S}-\mathrm{H}$ gel, which resulted in the creation of more $\mathrm{C}-\mathrm{S}-\mathrm{H}$ gel, less portlandite, smaller pore size, and higher strength than regular concrete. In this scenario, 30\% substitution of RHA value is the best choice (Padhi, R et al.2017). The addition of recycled concrete aggregates and rice husk ash in concrete, according to numerous researchers, has a major effect on the actions of concrete. Concrete mixes containing $100 \%$ coarse recycled concrete aggregates and $10 \%-15 \%$ rice husk ash, on the other hand, meet the design criteria for use in the construction industry. (Padhi, R et al.2017, Padhi, R et al.2018). For the M30 grade of concrete, Kulkarni, Makarand S, et al (2014) show that replacing cement with Rice Husk Ash increases compressive strength enhances workability, and achieves the target strength at a $20 \%$ replacement rate. (Kulkarni, Makarand $\mathrm{S}$, et al 2014). As a result, it is vital to propose effective construction methods for the reuse of waste building materials in the concrete manufacturing industry (Akiyoshi, Y et al.2011, Taku, K. J et al.2015)

\section{OBJECTIVES}

The general objectives of this study will investigate the following objectives.

- To check the workability of recycled aggregate concrete with replacement of cement by different proportions $(0 \%, 7.5 \%, 10 \%, 12.5 \%$, $15 \%$, and $17.5 \%$ ) of Rice Husk Ash. 
- To check the Compressive strength (compression test, Rebound hammer test) of recycled aggregate concrete with replacement of cement by different proportions $(0 \%, 7.5 \%$, $10 \%, 12.5 \%, 15 \%$, and $17.5 \%$ ) of Rice Husk Ash.

\section{EXPERIMENTAL PROGRAM}

\subsection{Materials and Methodology}

Ordinary Portland cement of Maple leaf brand is used for concrete making and detailed properties of cement are given in Table 1. In the production of concrete, the binder has prime importance and it is very important to complete the experimental program within designed period from the purchasing date of cement to maintain the quality as well as to decrease the contrary result on the properties of concrete through the storage.

\begin{tabular}{|c|c|c|}
\hline Sr.no. & Property & Result \\
\hline 1 & Consistency & 39 \\
\hline 2 & Initial setting time (min) & 115 \\
\hline 3 & Final setting time $(\mathrm{min})$ & 390 \\
\hline 4 & Fineness $(\%)$ & 95.3 \\
\hline 5 & Specific gravity $(\mathrm{gm} / \mathrm{cm} 3)$ & 3.12 \\
\hline
\end{tabular}

Table 1. Physical properties of cement

The recycled coarse aggregate is used for the experimental program collected from the destroyed building material which contains R.C.C structure residue and size obtained for both type of aggregates (normal and recycled) from sieve analysis (ASTM C 116-04, C $117-05$ ) is $20 \mathrm{~mm}$ down. Locally available sand such as Chenab sand is used as filler material or fine aggregate and other properties of aggregates are shown in Table 2. In this research rice husk ash is used as partial replacement of binder so it is obtained by burning the rice husk and grinded it well to obtain a fine powder. The normal tap water that is suitable for drinking having $\mathrm{P}_{\mathrm{H}}$ ranges 6-8 is used.

\begin{tabular}{|c|c|c|c|c|}
\hline 1 & $\begin{array}{c}\text { Specific gravity } \\
\text { (SSD)(gm/cm3) }\end{array}$ & 2.74 & Aggregate & Aggregate \\
\hline 2 & $\begin{array}{c}\text { Water } \\
\text { absorption (\%) }\end{array}$ & 1.21 & 1.13 & 2.43 \\
\hline 3 & $\begin{array}{c}\text { Fineness } \\
\text { modulus(mm) }\end{array}$ & 2.55 & 6.89 & 6.57 \\
\hline
\end{tabular}

Table 2. Aggregate properties

After performing material testing mix-design is performed and concrete is produced for target design strength of $21 \mathrm{MPa}$ or 3000 psi with approximate mixing ratio of $1: 2: 4$ and $\mathrm{W} / \mathrm{C}$ of 0.50 . A control mix M1 in which $0 \%$ rice husk ash is used is prepared to compare the results which are obtained with different percentage replacements of rice husk ash. In this research, cement is replaced with different proportions of rice husk ash including 7.5, 10, 12.5,15 and $17.5 \%$ respectively. Around six concrete mixes are prepared. Normal and acid curing is carried out at the ages of 3, 7, 14,21 and 28 days. The $\mathrm{p}_{\mathrm{H}}$ of acidic water is set at a value of 5 which is shown in figure. 1 .The concrete mixes are also cured in rapid curing tank for 28.5 hours. In the whole experimental program, approximately 90 cylinders are casted and tested. The compressive strength of concrete mixes is determined by compression test. Linear regression is carried out to compare the compressive strength result obtained both from experimental and mathematical analysis. The mixing detail and cylinder casting schedule is shown in Table 3 and Table 4

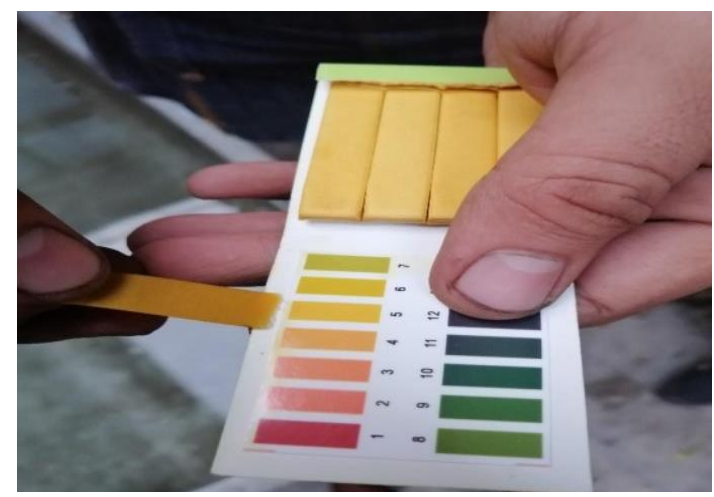

Figure. 1. PH value of water

\begin{tabular}{|c|c|c|c|c|}
\hline $\begin{array}{c}\text { Sr. } \\
\text { no. }\end{array}$ & Property & $\begin{array}{c}\text { Fine } \\
\text { aggregates }\end{array}$ & $\begin{array}{c}\text { Natural } \\
\text { Coarse }\end{array}$ & $\begin{array}{c}\text { Recycled } \\
\text { coarse }\end{array}$ \\
\hline
\end{tabular}

\begin{tabular}{|c|c|c|}
\hline Sr.No. & Type of Mixes & Replacement \\
\hline 1 & $\mathrm{M} 1$ & $\mathrm{C}(100 \%)+\mathrm{S}+\mathrm{RCA}+0 \%$ RHA \\
\hline 2 & $\mathrm{M} 2$ & $\mathrm{C}(92.5 \%)+\mathrm{S}+\mathrm{RCA}+7.5 \%$ RHA \\
\hline 3 & $\mathrm{M} 3$ & $\mathrm{C}(90 \%)+\mathrm{S}+\mathrm{RCA}+10 \% \mathrm{RHA}$ \\
\hline 4 & $\mathrm{M} 4$ & $\mathrm{C}(87.5 \%)+\mathrm{S}+\mathrm{RCA}+12.5 \% \mathrm{RHA}$ \\
\hline 5 & $\mathrm{M} 5$ & $\mathrm{C}(85 \%)+\mathrm{S}+\mathrm{RCA}+15 \% \mathrm{RHA}$ \\
\hline 6 & $\mathrm{M} 6$ & $\mathrm{C}(82.5 \%)+\mathrm{S}+\mathrm{RCA}+17.5 \% \mathrm{RHA}$ \\
\hline
\end{tabular}

Table 3. Replacement detail of materials 


\begin{tabular}{|c|c|c|c|c|c|c|c|c|c|c|c|c|}
\hline \multirow{2}{*}{ Sr.No. } & \multirow{2}{*}{$\begin{array}{c}\text { Type } \\
\text { of } \\
\text { Mixes }\end{array}$} & \multirow{2}{*}{$\begin{array}{c}\mathbf{2 8 . 5} \\
\text { Hr. }\end{array}$} & $\begin{array}{c}\mathbf{3} \\
\text { days }\end{array}$ & $\mathbf{7}$ days & $\begin{array}{c}\mathbf{1 4} \\
\text { days }\end{array}$ & $\begin{array}{c}\mathbf{2 1} \\
\text { days }\end{array}$ & $\begin{array}{c}\mathbf{2 8} \\
\text { days }\end{array}$ & $\begin{array}{c}\mathbf{3} \\
\text { days }\end{array}$ & 7ays & $\begin{array}{c}\mathbf{1 4} \\
\text { days }\end{array}$ & $\begin{array}{c}\mathbf{2 1} \\
\text { days }\end{array}$ & $\begin{array}{c}\mathbf{2 8} \\
\text { days }\end{array}$ \\
\hline 1 & M1 & 3 & 3 & 3 & 3 & 3 & 3 & 3 & 3 & 3 & 3 & 3 \\
\hline 2 & M2 & 3 & 3 & 3 & 3 & 3 & 3 & 3 & 3 & 3 & 3 & 3 \\
\hline 3 & M3 & 3 & 3 & 3 & 3 & 3 & 3 & 3 & 3 & 3 & 3 & 3 \\
\hline 4 & M4 & 3 & 3 & 3 & 3 & 3 & 3 & 3 & 3 & 3 & 3 & 3 \\
\hline 5 & M5 & 3 & 3 & 3 & 3 & 3 & 3 & 3 & 3 & 3 & 3 & 3 \\
\hline 6 & M6 & 3 & 3 & 3 & 3 & 3 & 3 & 3 & 3 & 3 & 3 & 3 \\
\hline
\end{tabular}

Table 4. Casting and curing detail

\section{RESULTS AND DISCUSSIONS}

The experimental consequences are analyzed so as to assess the impact of rice husk ash by the replacement of cement in recycled coarse aggregate concrete production at different curing conditions.

The slump test is performed to measure the workability of recycled aggregate concrete by the replacement of cement with different percentages of rice husk ash and the measuring method and consequences are shown in figure.2.

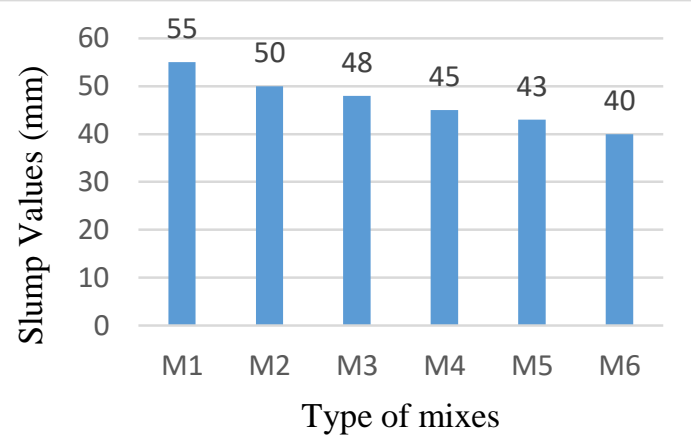

Figure. 2. Slump values
Slump test results indicate the reduction in workability of test sample as the percentage of rice husk ash is increased in recycled coarse aggregate concrete. The value of slump for mix M1 is $55 \mathrm{~mm}$ which is compared to mix M6 having slump value of $40 \mathrm{~mm}$. This reduction in slump values is approximately $27.27 \%$ as compared to mix M1 $(0 \%$ RHA $)$. The reason of reduction in workability is due to the more water absorbing capacity of recycled aggregates as well as rice husk ash. To overcome this problem, the re-cycled coarse aggregates are soaked in water approximately for twenty to thirty minutes before mixing of concrete.

The recycled aggregate concrete mixture is prepared by the replacement of cement with different proportions of rice husk ash including 0, 7.5, 10, 12.5, 15 and 17.5\% respectively. The compressive strength of cylinders is determined by using compressive strength machine at the ages of 3,7,14,21 and 28 days for both normal and acid water curing, as well as at 28.5 hour curing in rapid curing tank and the determined values are presented in Table 5.

\begin{tabular}{|c|c|c|c|c|c|c|c|c|c|c|c|c|c|c|}
\hline \multirow{3}{*}{$\begin{array}{l}\text { Sr. } \\
\text { No. }\end{array}$} & \multirow{3}{*}{$\begin{array}{c}\text { Type } \\
\text { of Mix }\end{array}$} & \multirow{3}{*}{$\begin{array}{l}\text { Rice Husk } \\
\quad \text { Ash } \\
\text { Percentage }\end{array}$} & \multicolumn{12}{|c|}{ Average Compressive Strength (MPa) } \\
\hline & & & \multicolumn{6}{|c|}{ Normal Water Curing } & \multicolumn{6}{|c|}{ Acidic Water Curing } \\
\hline & & & \begin{tabular}{|c|}
28.5 \\
Hours
\end{tabular} & 3 Days & 7 Days & 14 Days & 21 Days & 28 Days & \begin{tabular}{|c|}
28.5 \\
Hours
\end{tabular} & 3 Days & 7 Days & 14 Days & 21 Days & 28 Days \\
\hline 1 & M1 & $0 \%$ & 14.91 & 9.23 & 16.48 & 20.65 & 21.53 & 22.89 & 12.51 & 9.17 & 15.72 & 20.41 & 21.01 & 22.67 \\
\hline 2 & M2 & $7.5 \%$ & 13.03 & 8.33 & 13.66 & 18.72 & 19.48 & 20.76 & 11.09 & 8.03 & 13.55 & 17.99 & 19.01 & 20.19 \\
\hline 3 & M3 & $10 \%$ & 14.37 & 8.76 & 14.36 & 19.28 & 20.09 & 21.34 & 11.92 & 8.49 & 14.11 & 18.15 & 18.76 & 21.03 \\
\hline 4 & M4 & $12.5 \%$ & 12.09 & 8.01 & 12.97 & 18.05 & 18.67 & 19.98 & 11.13 & 7.53 & 12.29 & 16.91 & 16.91 & 19.08 \\
\hline 5 & M5 & $15 \%$ & 11.58 & 7.52 & 12.79 & 16.76 & 17.35 & 18.67 & 9.63 & 6.99 & 11.82 & 15.29 & 15.82 & 17.88 \\
\hline 6 & M6 & $17.5 \%$ & 10.37 & 7.11 & 11.38 & 15.83 & 16.09 & 17.55 & 8.82 & 6.18 & 10.77 & 14.28 & 14.73 & 16.81 \\
\hline
\end{tabular}

Table 5. Compression test results

It is clearly evident from the above results that the mix M3 with 10\% Rice Husk Ash shows the maximum compressive strength in all curing environments.

\section{LINEAR REGRESSION ANALYSIS}

To develop a mathematical model in the form of an equation, we used linear regression analysis. This mathematical equation (model) is a connection (association) between two variables. Linear regression analysis is a method to represent the given data through a mathematical model (equation). This model is achieved by representing the obtained data in the form of a graph and then inducing a linear trend line in the data. The linear trend line is then represented by a mathematical linear equation whose authenticity is determined by $\mathrm{R}^{2}$ factor. 
In this research, two different approaches have been used while carrying out linear regression. In first approach, the explanatory variable " $\mathrm{X}$ " denoted the number of day for which compressive strength (dependent variable "Y") is to be determined. In the second approach, the content of RHA is explanatory variable " $X$ " and compressive strength is dependent variables "Y". A straight line is represented by a linear equation mathematically, it is stated in general as $\mathrm{Y}=\mathrm{mX}+\mathrm{c}$, where, $\mathrm{Y}$ (which in our case is the compressive strength of RHA based recycled aggregate concrete) is the dependent variable and $\mathrm{X}$ (which in $1^{\text {st }}$ case is the number of days, and $2^{\text {nd }}$ case is the content of RHA) is the explanatory variable, " $\mathrm{m}$ " this linear equation shows the slope of the line and "c" in this general linear equation shows $y$-intercept when the value of " $\mathrm{x}$ " is null.

\subsection{R-Squared}

$\mathrm{R}^{2}$ is a type of measure for validating the regression equation obtained after carrying out regression analysis for a given data. The value of $\mathrm{R}^{2}$ ranged between $0 \%$ to $100 \%$. If the value of $\mathrm{R}^{2}$ is near $0 \%$, it means that the equation is not reliable to calculate the data with precision. Higher value (near to $100 \%$ ) of $\mathrm{R}^{2}$ shows that the equation is more authentic and the value calculated through this equation will be more near to the original value. Conservatively, the value of $\mathrm{R}^{2}$ greater than $80 \%$ is considered to be acceptable.

Table 5 shows the results of compressive testing. These compressive strengths have been shown graphically through scatter plots (xy-graph). The mathematical model is obtained by inducing a trend line in the graph. All the variations of RHA have been plotted in Figure 34. For each variation of RHA the mathematical equation has been shown on the graph.

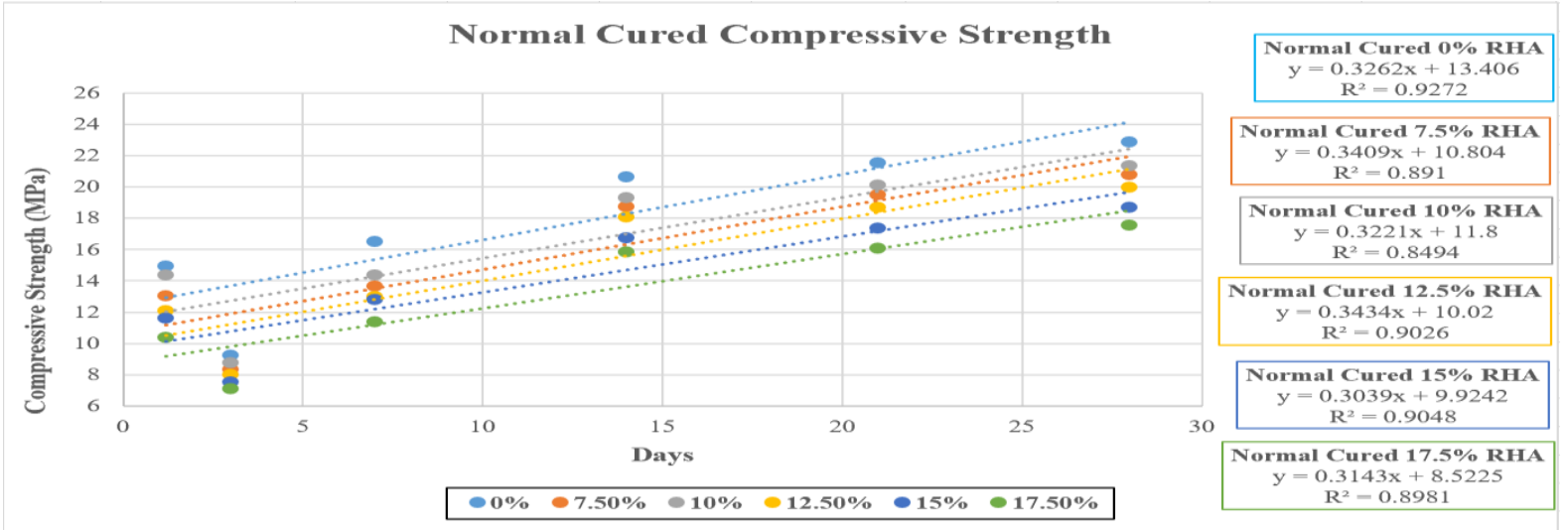

Figure. 3. Linear regression of normal cured RHA based recycled aggregate concrete.

Figure 3. Shows linear regression analysis for RHA based recycled aggregate concrete, cured in normal water. It is clearly pragmatic that all linear equations has accuracy of more than $80 \%$. The minimum $\mathrm{R}^{2}$ value is almost $85 \%$, obtained for M3 concrete. While, maximum $\mathrm{R}^{2}$ value is almost $93 \%$, obtained for M1 concrete.

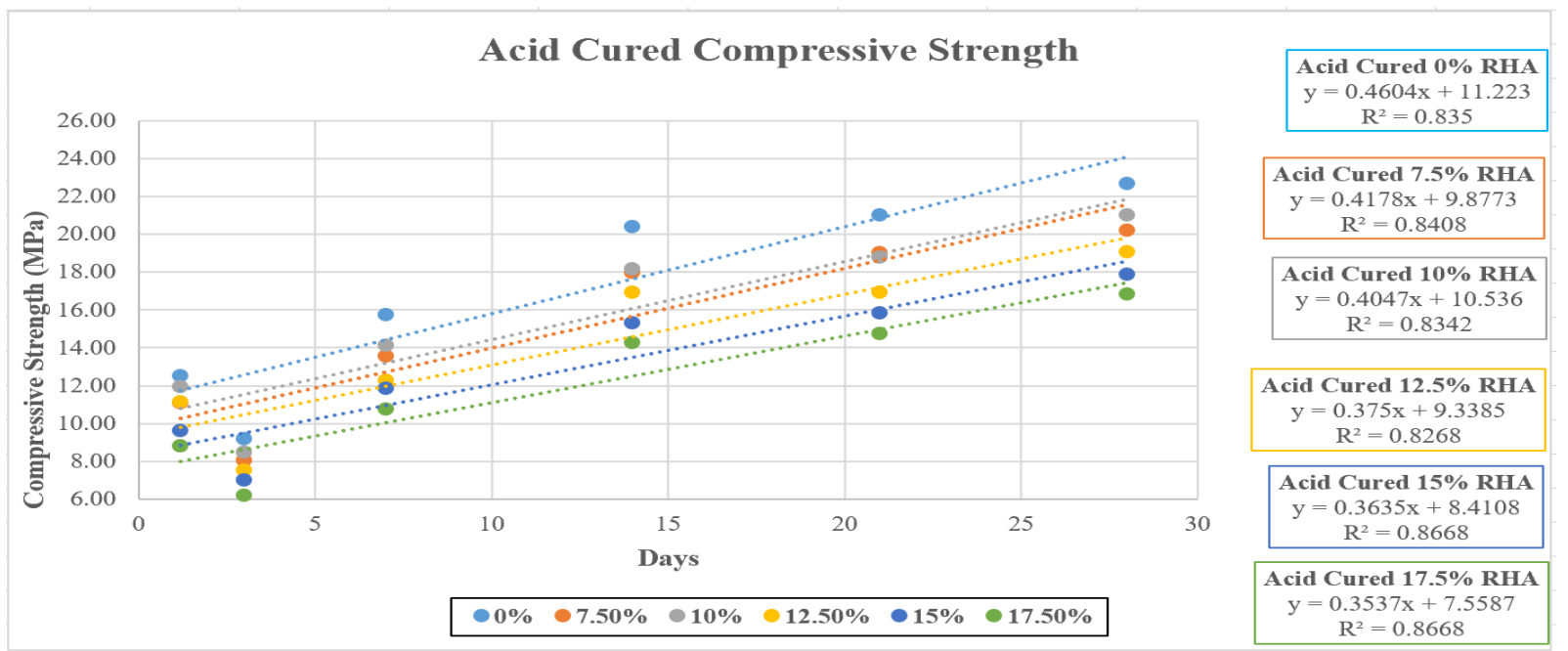

Figure. 4. Linear regression of acid cured RHA based recycled aggregate concrete.

Figure 4. Shows linear regression analysis for RHA based recycled aggregate concrete, cured in acidic water. It is clearly perceived that all linear equations have accuracy of more than $80 \%$. The minimum $\mathrm{R}^{2}$ value is almost $83 \%$, obtained for M4 concrete. While, maximum 
$\mathrm{R}^{2}$ value is almost $86 \%$, obtained for M5 and M6 concrete.

5.2 Difference between Actual and Forecasted Values
The mathematical equations obtained after carrying out the regression analysis are checked for forecasting the values of the compressive strength. These values with the percentage variation from original results are listed in Tables 6-7.

\begin{tabular}{|c|c|c|c|c|c|c|c|c|c|c|c|c|c|c|c|}
\hline \multicolumn{16}{|c|}{ Normal Cured } \\
\hline \multirow{3}{*}{ RHA } & \multicolumn{15}{|c|}{ Compressive Strength (MPa) } \\
\hline & \multicolumn{3}{|c|}{ 28.5 Hours } & \multicolumn{3}{|c|}{ 7Days } & \multicolumn{3}{|c|}{14 Days } & \multicolumn{3}{|c|}{21 Days } & \multicolumn{3}{|c|}{28 Days } \\
\hline & \multicolumn{6}{|c|}{ Experimental| Forecasted Variation $(\%) \mid$ Experimental| Forecasted Variation } & Experimen & Forecaster & |ariation & Experimenta & Forecasted & Variation & Experimente & Forecaster & Variation $1 \%$ \\
\hline $0 \%$ & 14.91 & 13.79 & 7,51 & 16.48 & 15.69 & 4.80 & 20.65 & 17.97 & 12.96 & 21.53 & 20.26 & 5.92 & 22.89 & 22.54 & 1.53 \\
\hline $7.50 \%$ & 13.03 & 11.21 & 13.97 & 13.66 & 13.19 & 3.44 & 18.72 & 15.58 & 16.79 & 19.48 & 17.96 & 7.79 & 20.76 & 20.35 & 1.98 \\
\hline $10 \%$ & 14.37 & 12,18 & 15.24 & 14,36 & 14,05 & 2,13 & 19.28 & 16.31 & 15.41 & 20.09 & 18.56 & 7,60 & 21.34 & 20.82 & 2.44 \\
\hline $12.50 \%$ & 12.09 & 10.43 & 13.73 & 12.97 & 12.42 & 4.21 & 18.05 & 14.83 & 17.85 & 18.67 & 17.23 & 7.71 & 19.98 & 19.64 & 1.73 \\
\hline $15 \%$ & 11.58 & 10.29 & 11.14 & 12.79 & 12.05 & 5.77 & 16.76 & 14,18 & 15.40 & 17,35 & 16.31 & 6.02 & 18.67 & 18.43 & 1.27 \\
\hline $17.50 \%$ & 10.37 & 8.90 & 14,18 & 11.38 & 10.72 & 5.78 & 15.83 & 12.92 & 18.37 & 16.09 & 15.12 & 6.01 & 17.55 & 17.32 & 1.29 \\
\hline
\end{tabular}

Table. 6. Percentage variation between actual and forecasted compressive strength using linear equations for normal cured RHA based recycled aggregate concrete

Table 6 shows the validation of linear equations obtained through linear regression analysis. It can be observed that all the forecasted values, obtained from linear equation values, are in range and maximum variation between actual (experimental) values and predicted (forecasted) values is less than $20 \%$. For 28.5 hours accelerated cured compressive strength, the maximum variation between actual (experimental) values and predicted (forecasted) values is almost $15 \%$, for M6 concrete. While, minimum variation is almost $7.5 \%$, for M1 concrete.

Whereas, for 28 Days normal cured compressive strength, the maximum variation between actual (experimental) values and predicted (forecasted) values is almost $2.5 \%$, for M3 concrete. While, minimum variation is almost $1.2 \%$, for M5 concrete.

\begin{tabular}{|c|c|c|c|c|c|c|c|c|c|c|c|c|c|c|c|}
\hline \multicolumn{16}{|c|}{ Acid Cured } \\
\hline \multirow{3}{*}{ RHA } & \multicolumn{15}{|c|}{ Compressive Strength (MPa) } \\
\hline & \multicolumn{3}{|c|}{28.5 Hours } & \multicolumn{3}{|c|}{7 Days } & \multicolumn{3}{|c|}{14 Days } & \multicolumn{3}{|c|}{21 Days } & \multicolumn{3}{|c|}{28 Days } \\
\hline & Experimenta & Forecaste & Variation |\% & Experimen & | Forecaste & ed Variation (\% & 6) Experiments & Forecaste & Variation & Experiment & Forecaste & d Variation (9 & c) Experiment & Forecasted & Variation (\%) \\
\hline $0 \%$ & 12.51 & 11.77 & 5.92 & 15.72 & 14.45 & 8.11 & 20.41 & 17.67 & 13.43 & 21.01 & 20.89 & 0.56 & 22.67 & 24.11 & 5.99 \\
\hline $7,50 \%$ & 11.09 & 10,37 & 6.49 & 13.55 & 12.80 & 5.52 & 17.99 & 15.73 & 12.58 & 19.01 & 18.65 & 1.89 & 20.19 & 21.58 & 6.42 \\
\hline $10 \%$ & 11.92 & 11.02 & 7.55 & 14.11 & 13.37 & 5.25 & 18.15 & 16.20 & 10.73 & 18.76 & 19.03 & 1.44 & 21.03 & 21.87 & 3.83 \\
\hline $12.50 \%$ & 11.13 & 9.78 & 12.13 & 12.29 & 11.96 & 2.66 & 16.91 & 14.59 & 13.73 & 16.91 & 17.21 & 1.76 & 19.08 & 19.84 & 3.82 \\
\hline $15 \%$ & 9.63 & 8.84 & 8.20 & 11.82 & 10.96 & 7.32 & 15.29 & 13.50 & 11.71 & 15.82 & 16.04 & 1.40 & 17.88 & 18.59 & 3.81 \\
\hline $17.50 \%$ & 8.82 & 7.98 & 9.52 & 10.77 & 10.03 & 6.83 & 14.28 & 12.51 & 12.39 & 14.73 & 14.99 & 1.71 & 16.81 & 17.46 & 3.74 \\
\hline
\end{tabular}

Table. 7. Percentage variation between actual and forecasted compressive strength using linear equations for acid cured RHA based recycled aggregate concrete

Table 7 shows the validation of linear equations obtained through linear regression analysis. It can be observed that all the forecasted values, obtained from linear equation values, are in range and maximum variation between actual (experimental) values and predicted (forecasted) values is less than $20 \%$. For 28.5 hours accelerated cured compressive strength, the maximum variation between

\subsection{Evaluation of Compressive Strengths from Various Curing Conditions}

A comparison is made between compressive strength obtained after curing the concrete samples in normal actual (experimental) values and predicted (forecasted) values is almost $12 \%$, for M4 concrete. While, minimum variation is almost $6 \%$, for M1 concrete. Whereas, for 28 Days acid cured compressive strength, the maximum variation between actual (experimental) values and predicted (forecasted) values is almost $6.5 \%$, for M2 concrete. While, minimum variation is almost $3.7 \%$, for M6 concrete.

water with the compressive strength obtained after curing concrete in acidic water for 28.5 Hours, 7, 14, 21 and 28 Days compressive strengths for each variation of Rice Husk Ash. The comparison is listed in Table 8 . 


\begin{tabular}{|c|c|c|c|c|c|c|c|c|c|c|c|c|c|c|c|}
\hline \multicolumn{16}{|c|}{ Comparison of Curing Conditions } \\
\hline \multirow{3}{*}{ RHA } & \multicolumn{15}{|c|}{ Compressive Strength (MPa) } \\
\hline & \multicolumn{3}{|c|}{28.5 Hours } & \multicolumn{3}{|c|}{7 Days } & \multicolumn{3}{|c|}{14 Days } & \multicolumn{3}{|c|}{21 Days } & \multicolumn{3}{|c|}{28 Days } \\
\hline & Normal & Acid & Variation (\%) I & Normal & Acid & Variation (\%) & Normal & Acid & Variation (\%) & Normal & Acid & Variation (\%) & Normal & Acid & Variation (\%) \\
\hline $0 \%$ & 14.91 & 12.51 & 16.10 & 16.48 & 15.72 & 4.61 & 20.65 & 20.41 & 1.16 & 21.53 & 21.01 & 2.42 & 22.89 & 22.7 & 0.96 \\
\hline $7.50 \%$ & 13.03 & 11.09 & 14.89 & 13.66 & 13.55 & 0.81 & 18.72 & 17.99 & 3.90 & 19.48 & 19.01 & 2.41 & 20.76 & 20.2 & 2.75 \\
\hline $10 \%$ & 14.37 & 11.92 & 17.05 & 14.36 & 14.11 & 1.74 & 19.28 & 18.15 & 5.86 & 20.09 & 18.76 & 6.62 & 21.34 & 21 & 1.45 \\
\hline $12.50 \%$ & 12.09 & 11.13 & 7.94 & 12.97 & 12.29 & 5.24 & 18.05 & 16.91 & 6.32 & 18.67 & 16.91 & 9.43 & 19.98 & 19.1 & 4.50 \\
\hline $15 \%$ & 11.58 & 9.63 & 16.84 & 12.79 & 11.82 & 7.58 & 16.76 & 15.29 & 8.77 & 17.35 & 15.82 & 8.82 & 18.67 & 17.9 & 4.23 \\
\hline $17.50 \%$ & 10.37 & 8.82 & 14.95 & 11.38 & 10.77 & 5.36 & 15.83 & 14.28 & 9.79 & 16.09 & 14.73 & 8.45 & 17.55 & 16.8 & 4.22 \\
\hline
\end{tabular}

Table. 8. Percentage variation between normal cured and acid cured compressive strength of RHA based recycled aggregate concrete

Table 8 shows that the compressive strength of concrete is reduced due to acid curing. It is clearly observed that all the values are within range of maximum variation less than $20 \%$. In case of accelerated curing, this reduction in compressive strength is increased as compared to in case of normal curing of 28 days. In case of accelerated (rapid) curing, the maximum variation between normal and acidic environment compressive strength is almost $17 \%$ for M3 concrete, while the minimum variation between normal and acidic environment compressive strength is almost $8 \%$, for M4 concrete.

Whereas, in case of 28-Days compressive strength the maximum variation between normal and acidic environment compressive strength is $4.5 \%$, for M4 concrete, while the minimum variation between normal and acidic environment compressive strength is almost $1 \%$, for M1 concrete.

\subsection{Comparison of Compressive Strengths from Different Curing Methods}

A comparison has been made between accelerated (rapid) curing and normal curing of 28 days for both curing environments. The percentage gain of 28 days compressive strength achieved by accelerated (rapid) curing, for both curing environment is listed in Table 9 .

\begin{tabular}{|c|c|c|c|c|c|c|c|}
\hline \multicolumn{8}{|c|}{ Comparison of Curing Conditions } \\
\hline \multirow{3}{*}{ RHA } & \multicolumn{2}{|c|}{ Compressive Strength (MPa) } & Percentage of Strength Achieved By Rapid Curing \\
\cline { 2 - 7 } & $\mathbf{2 8 . 5}$ Hours & \multicolumn{2}{|c|}{$\mathbf{2 8}$ Days } & \multicolumn{2}{c|}{ Normal Curing } & Acid Curing \\
\cline { 2 - 7 } & Normal & Acid & Normal & Acid & & & \\
\hline $\mathbf{0 \%}$ & 14.91 & 12.51 & 22.89 & 22.67 & 65.14 & 55.18 \\
\hline $\mathbf{7 . 5 0} \%$ & 13.03 & 11.09 & 20.76 & 20.19 & 62.76 & 54.93 \\
\hline $\mathbf{1 0 \%}$ & 14.37 & 11.92 & 21.34 & 21.03 & 67.34 & 56.68 \\
\hline $\mathbf{1 2 . 5 0} \%$ & 12.09 & 11.13 & 19.98 & 19.08 & 60.51 & 58.33 \\
\hline $\mathbf{1 5 \%}$ & 11.58 & 9.63 & 18.67 & 17.88 & 62.02 & 53.86 \\
\hline $\mathbf{1 7 . 5 0 \%}$ & 10.37 & 8.82 & 17.55 & 16.81 & 59.09 & 52.47 \\
\hline
\end{tabular}

Table 9. Percentage gain of 28 days compressive strength by rapid (accelerated) curing for RHA based recycled aggregate concrete

Table 9 clearly shows that the percentage gain of 28 days compressive strength for normal water cured concrete is higher that acidic water cured concrete in all the cases. It can be observed that, M3 concrete has maximum achievement of compressive strength through accelerated (rapid) curing method. In case of normal water cured, the compressive strength achieved through accelerated (rapid) curing is almost $67 \%$ of 28 -Days compressive strength, for M3 concrete. Whereas, in case of acidic water cured, the compressive strength achieved through accelerated (rapid) curing is almost 57\% of 28 -Days compressive strength, for M3 concrete.
5.5 Linear Regression Analysis w.r.t RHA content

All variation of rice husk ash are plotted in the graph and shown in Figure. 5-6. The mathematical models obtained after carrying out regression analysis is shown on the graph. 


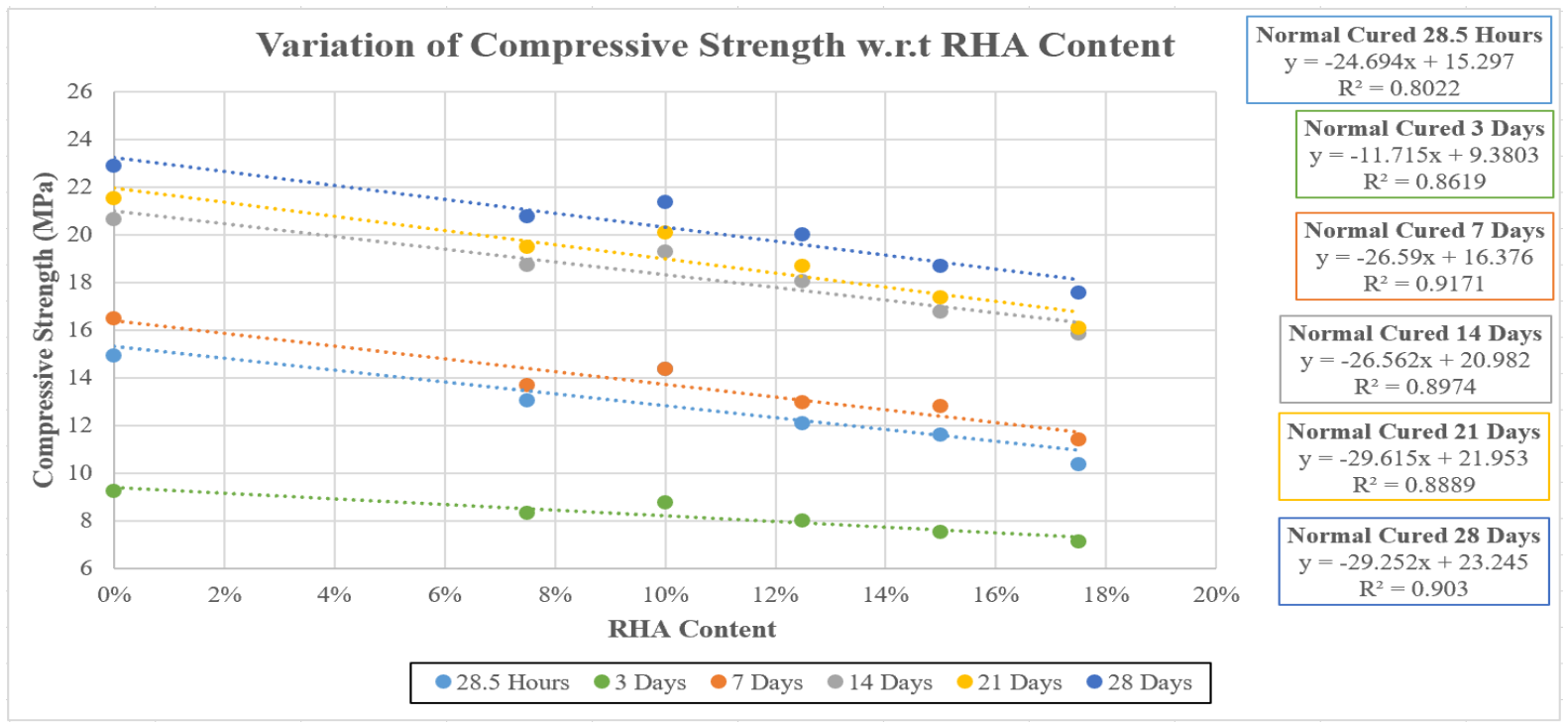

Figure. 5. Linear regression of normal cured RHA based recycled aggregate concrete w.r.t RHA content.

Figure 5. Shows linear regression analysis for RHA based recycled aggregate concrete, cured in normal water, w.r.t RHA content. It is clearly observed that all linear equations have accuracy of more than $80 \%$.
Minimum $\mathrm{R}^{2}$ value is almost $80 \%$, obtained for $\mathrm{M} 1$ concrete. While, maximum $\mathrm{R}^{2}$ value is almost $92 \%$, obtained for M3 concrete.
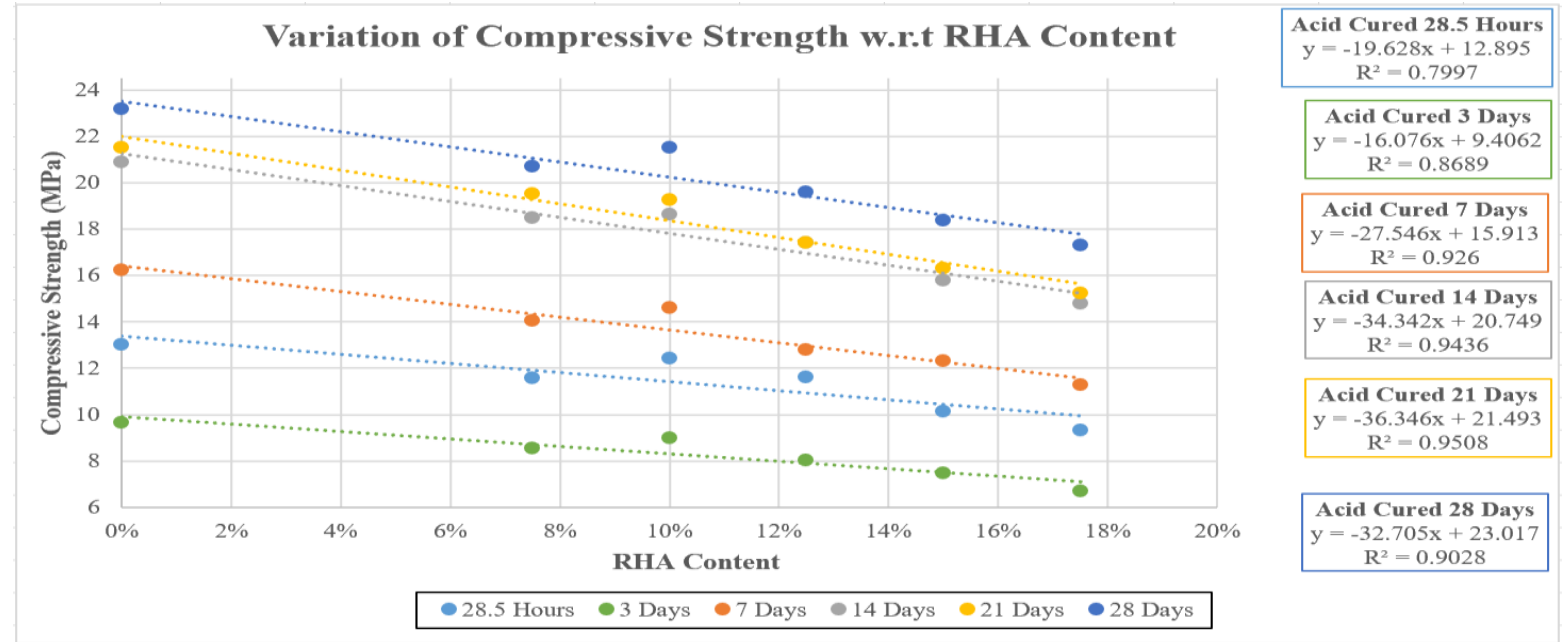

Figure. 6. Linear regression of acid cured RHA based recycled aggregate concrete w.r.t RHA content

Figure 6. Shows linear regression analysis for RHA based recycled aggregate concrete, cured in acidic water, w.r.t RHA content. It is clearly observed that all linear equations have accuracy of more than $80 \%$. Minimum $\mathrm{R}^{2}$ value is almost $80 \%$, obtained for M1 concrete. While, maximum $\mathrm{R}^{2}$ value is almost $95 \%$, obtained for M5 concrete.

\subsection{Variation between Actual and Forecasted Compressive Strength}

The results obtained from the regression analysis are verified for predicting the values of the compressive strength. The comparison between actual and predicted values is shown in Tables 10-11. 


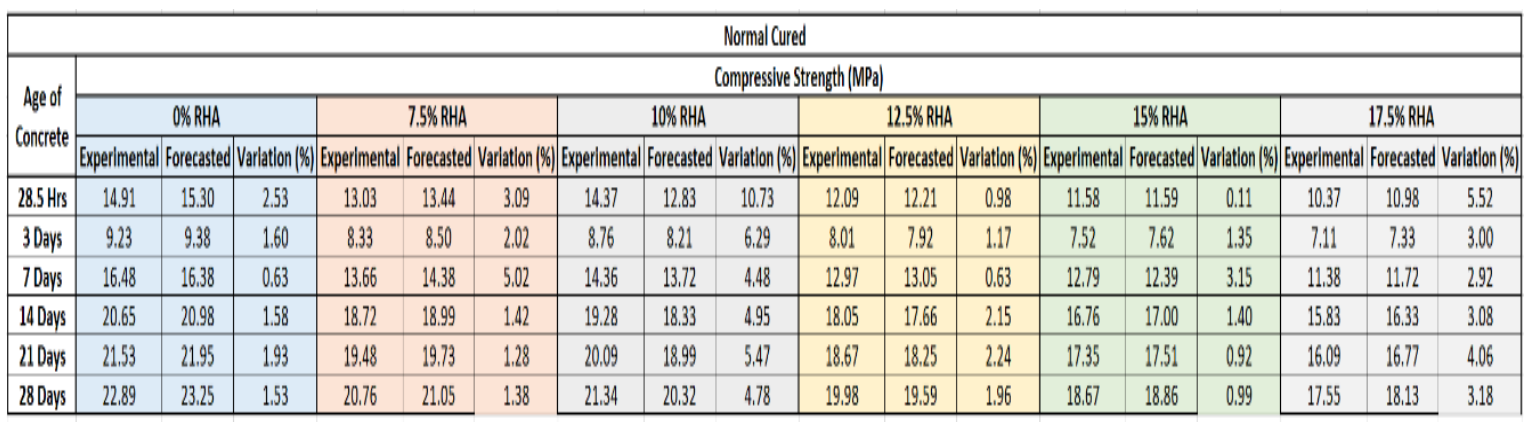

Table. 10. Percentage variation between actual and forecasted compressive strength using linear equations for normal cured RHA based recycled aggregate concrete

Table 10 shows the validation of linear equations obtained through linear regression analysis. It can be observed that all the forecasted values, obtained from linear equation values, are in range and maximum variation between actual (experimental) values and predicted (forecasted) values is less than $20 \%$. For 28.5 hours accelerated cured compressive strength, the maximum variation between actual (experimental) values and predicted (forecasted) values is almost $2.5 \%$, for M1 concrete. While, minimum variation is almost $0.5 \%$, for M3 concrete.

Whereas, for 28 Days normal cured compressive strength, the maximum variation between actual (experimental) values and predicted (forecasted) values is almost $5.5 \%$, for M1 concrete. While, minimum variation is almost $2.9 \%$, for M3 concrete.

\begin{tabular}{|c|c|c|c|c|c|c|c|c|c|c|c|c|c|c|c|c|c|c|}
\hline \multicolumn{19}{|c|}{ Acld Cured } \\
\hline \multirow{3}{*}{$\begin{array}{l}\text { Age of } \\
\text { Concrete }\end{array}$} & \multicolumn{18}{|c|}{ Compresslve Strength (MPa) } \\
\hline & \multicolumn{3}{|c|}{ O\% RHA } & \multicolumn{3}{|c|}{ 7.5\% RHA } & \multicolumn{3}{|c|}{ 10\% RHA } & \multicolumn{3}{|c|}{ 12.5\% RHA } & \multicolumn{3}{|c|}{ 15\% RHA } & \multicolumn{3}{|c|}{ 17,5\% RHA } \\
\hline & Experiments & Forecasted & |ariation| & 6) Experiment & | Forecaster & Variation & 4) Experimental & Forecasted & Variation |X & Experimental & Forecasted & Variation| & 4) Experiment & Forecasted & Variation |\% & Experiment & | Forecaster & ariation|y| \\
\hline $28.5 \mathrm{Hrs}$ & 12.51 & 12.90 & 2.99 & 11.09 & 11.42 & 2,91 & 11.92 & 10,93 & 8.29 & 11.13 & 10,44 & 6.19 & 9.63 & 9.95 & 3.22 & 8.82 & 9.46 & 6.77 \\
\hline 3 Days & 9.17 & 9.41 & 2.51 & 8.03 & 8.20 & 2.08 & 8.49 & 7.80 & 8.14 & 7.53 & 7.40 & 1.77 & 6.99 & 6.99 & 0.07 & 6.18 & 6.59 & 6.26 \\
\hline 7Days & 15.72 & 15.91 & 1.21 & 13.55 & 13.85 & 2.15 & 14.11 & 13.16 & 6.74 & 12.29 & 12.47 & 1.44 & 11.82 & 11.78 & 0.33 & 10.77 & 11.09 & 2.91 \\
\hline 14 Days & 20.41 & 20.75 & 1.63 & 17.99 & 18.17 & 1.01 & 18.15 & 17.31 & 4.60 & 16.91 & 16,46 & 2.68 & 15.29 & 15.60 & 1.97 & 19.28 & 19.74 & 3.12 \\
\hline 21 Days & 21.01 & 21.49 & 2.25 & 19.01 & 18.77 & -1.29 & 18.76 & 17.86 & 4.81 & 16.91 & 16.95 & 0.23 & 15.82 & 16.04 & 1.38 & 14.73 & 15.13 & 2.66 \\
\hline 28 Days & 22.67 & 23,02 & 1.51 & 20,19 & 20.56 & 1.82 & 21.03 & 19,75 & 6,10 & 19.08 & 18.93 & 0.79 & 17.88 & 18.11 & 1.28 & 16.81 & 17,29 & 2.80 \\
\hline
\end{tabular}

Table. 11. Percentage variation between actual and forecasted compressive strength using linear equations for normal cured RHA based recycled aggregate concrete

Table 11 shows the validation of linear equations obtained through linear regression analysis. It can be observed that all the forecasted values, obtained from linear equation values, are in range and maximum variation between actual (experimental) values and predicted (forecasted) values is less than $20 \%$. For 28.5 hours accelerated cured compressive strength, the maximum variation between actual (experimental) values and predicted (forecasted) values is almost 3\%, for M1 concrete. While, minimum variation is almost $1.2 \%$, for M3 concrete.

Whereas, for 28 Days acid cured compressive strength, the maximum variation between actual (experimental) values and predicted (forecasted) values is almost 7\%, for M1 concrete. While, minimum variation is almost $2.6 \%$, for M5 concrete.

\section{CONCLUSIONS}

In the present work, the workability and compressive strength of re-cycled aggregate concrete is determined by the replacement of cement with numerous percentages of rice husk ash. It is observed from the experimental results that the workability of recycled aggregate concrete is reduced as we increased the quantity of rice husk ash. The reason of this reduction in workability is due to high water absorption of recycled aggregates and rice husk ash. The slump value for recycled aggregate concrete with $0 \%$ rice husk ash is $55 \mathrm{~mm}$ and still recycled aggregate concrete remains workable( slump values $\approx 50 \mathrm{~mm}$ ) by the use of 10 to $15 \%$ of rice husk ash as shown by the experimental results which is also related to previous research (Padhi, $\mathrm{R}$ et al 2018). Linear regression analysis is carried out to determine the compressive strength of concrete to compare the experimental values of strength. The compressive strength of recycled aggregate concrete with normal and acid curing is decreased by increasing the percentages of rice husk ash. It is also observed that at 28- days of normal water curing for mix M1,M2,M3,M4,M5 and M6 the compressive strength is increased by $0.96 \%, 2.74 \%$ $1.45 \%, 4.50 \%, 4.23 \%$ and $4.22 \%$ respectively as compared to the compressive strength values at 28 days of acid water curing. Therefore, the research findings show that recycled aggregate concrete with 10 to $12 \%$ of rice husk ash is suitable for properties of concrete. The acid water curing has damaging impacts on hardened 
properties of concrete as it reduced the compressive strength of concrete as compared to normal water curing.

\section{ACKNOWLEDGMENT}

This research has been possible by the Grace and Help of ALMIGHTY ALLAH. We wish to thank the department of Civil Engineering and Technology of The University of Lahore for providing all the equipment used in this research.

\section{References}

Akinyemi, Banjo, Temidayo E. Omoniyi, Olugbenga Elemile, and Oluwafemi Arowofila. "Innovative Husk-Crete Building Materials from Rice Chaff and Modified Cement Mortars." Acta Technologica Agriculturae 23.2 (2020): 6772.

Terela, Ester, et al. "Analysis of the variables that affect the strength of concrete with recycled aggregates from prefabricated pipes." Congreso Internacional de Construcción Sostenible y Soluciones Ecoeficientes $\left(2^{\circ}\right.$. 2015. Sevilla). Universidad de Sevilla, Departamento de Construcciones Arquitectónicas I, 2015

García-González, Julia, et al. "Pre-saturation technique of the recycled aggregates: Solution to the water absorption drawback in the recycled concrete manufacture." Materials 7.9 (2014): 6224-6236.

Ben Nakhi, Ammar, and Jasem M. Alhumoud. "Effects of Recycled Aggregate on Concrete Mix and Exposure to Chloride." Advances in Materials Science and Engineering2019 (2019).

Jayakody, S., A. M. Z. Zimar, and R. A. L. M. Ranaweera "Potential use of recycled construction and demolition waste aggregates for non-structural concrete applications." (2018).

Hadavand, Bahareh, and Reza Imaninasab. "Assessing the influence of construction and demolition waste materials on workability and mechanical properties of concrete using statistical analysis." Innovative Infrastructure Solutions 4.1 (2019): 29.

Abdel-Hay, Ahmed Shaban. "Properties of recycled concrete aggregate under different curing conditions." HBRC journal13.3 (2017): 271-276

Padhi, R., and B. Mukharjee. "Effect of Rice Husk Ash on Compressive Strength of Recycled Aggregate Concrete." J. Basic Appl. Eng. Res 4 (2017): 356-359.

Khaoula, Naouaoui, Bouyahyaoui Azzeddine, and Cherradi Toufik. "Impact of Using Recycled Aggregates on
Compressive Strength of Concrete." Proceedings of the 3rd International Conference on Smart City Applications. ACM, 2018.

Salehlamein, Fathei Ramadan, Mochamad Solikin, and I. Sunarjono. "Effect of recycled coarse aggregate on concrete properties." International Journal of Innovative Research in Science, Engineering and Technology 4.1 (2015): 1906019068.

Adnan, Suraya Hani, Lee Yee Loon, Ismail Abdul Rahman, Hamidah Mohd Saman, Mia Wimala Soejoso Fakulti Kejuruteraan Awam dan Alam Sekitar. "Compressive strength of recycled aggregate concrete with various percentage of recycled aggregate." (2007)

Padhi, Rupali Subhasmita, et al. "Influence of incorporation of rice husk ash and coarse recycled concrete aggregates on properties of concrete." Construction and Building Materials 173 (2018): 289-297.

Fawzy, Yasser Abdelghany. "Impact of recycled gravel obtained from low or medium concrete grade on concrete properties." HBRC Journal 14.1 (2018): 1-8.

Meddah, M. S., et al. "Mechanical and microstructural characterization of rice husk ash and $\mathrm{Al} 2 \mathrm{O} 3$ nanoparticles modified cement concrete." Construction and Building Materials 255 (2020): 119358

Koushkbaghi, Mahdi, et al. "Acid resistance and durability properties of steel fiber-reinforced concrete incorporating rice husk ash and recycled aggregate." Construction and Building Materials 202 (2019): 266-275.

Praveenkumar, T. R., M. M. Vijayalakshmi, and M. S. Meddah. "Strengths and durability performances of blended cement concrete with $\mathrm{TiO} 2$ nanoparticles and rice husk ash." Construction and Building Materials 217 (2019): 343351.

Kulkarni, Makarand Suresh, et al. "Effect of rice husk ash on properties of concrete." Journal of Civil Engineering and Environmental Technology 1.1 (2014): 26-29.

Habeeb, Ghassan Abood, and Hilmi Bin Mahmud. "Stud on properties of rice husk ash and its use as cemer replacement material." Materials research 13.2 (2010): 185 190.

Akiyoshi, Y., Sato, T. Otani, K Ueda, N. Ito and H. Okada"Study on compressive strength of concrete using low quality recycled coarse aggregates." Proceedings of 36th Conference on Our World in Concrete \& Structures Singapore. 2011.

Taku, K. J., Amartey, D. Y., \& Kassar, T. (2015). Effect of acidic curing environment on the strength and durability of concrete. Civil and Environmental Research, 7 (12): 8-13. www. iiste. org. 